\title{
Evaluation of the Effects of Er,Cr:YSGG Laser, Ultrasonic Scaler and Curette on Root Surface Profile Using Surface Analyser and Scanning Electron Microscope: An In Vitro Study
}

\author{
Shipra Arora ${ }^{1 *}$, Arundeep Kaur Lamba², Farrukh Faraz ${ }^{2}$, Shruti Tandon ${ }^{2}$, Abdul Ahad ${ }^{3}$ \\ ${ }^{1}$ Department of Public Health Dentistry, Maulana Azad Institute of Dental Sciences, New Delhi, India \\ ${ }^{2}$ Department of Periodontics, Maulana Azad Institute of Dental Sciences, New Delhi, India \\ ${ }^{3}$ Department of Periodontics, Dr. Ziauddin Ahmad Dental College, Aligarh Muslim University, Aligarh, India
}

\author{
*Correspondence to \\ Dr. Shipra Arora, MDS; \\ Department of Public Health \\ Dentistry, Maulana Azad Institute \\ of Dental Sciences, Bahadur Shah \\ Zafar Marg, New Delhi - 110002, \\ India. \\ Email: \\ dr.shipraarora09@gmail.com
}

Published online 27 October 2016

\section{Introduction}

Periodontal therapy is directed towards complete removal of organized plaque matrix, calculus and diseased cementum to arrest the progression of disease. Thorough mechanical debridement allows adherence of fibroblast to previously diseased and non-diseased areas of the roots, a pre-requisite for the regeneration of lost periodontal tissues. This therapy is primarily based on scaling and root

\begin{abstract}
Introduction: The periodontal therapy is primarily targeted at removal of dental plaque and plaque retentive factors. Although the thorough removal of adherent plaque, calculus and infected root cementum is desirable, it is not always achieved by conventional modalities. To accomplish more efficient results several alternative devices have been used. Lasers are one of the most promising modalities for nonsurgical periodontal treatment as they can achieve excellent tissue ablation with strong bactericidal and detoxification effects.

Methods: Thirty freshly extracted premolars were selected and decoronated. The mesial surface of each root was divided vertically into four approximately equal parts. These were distributed into four group based on the root surface treatment. Part $A(n=30)$ was taken as control and no instrumentation was performed. Part B $(n=30)$ was irradiated by Erbium, Chromium doped Yttrium Scandium Gallium Garnet (Er,Cr:YSGG) laser. Part C $(n=30)$ was treated by piezoelectric ultrasonic scaler. Part $D(n=30)$ was treated by Gracey curette. The surface roughness was quantitatively analyzed by profilometer using roughness average (Ra) value, while presence of smear layer, cracks, craters and melting of surface were analyzed using scanning electron microscope (SEM). The means across the groups were statistically compared with control using Dunnett test.

Results: Among the test groups, Er,Cr:YSGG laser group showed maximum surface roughness (mean Ra value of $4.14 \mu \mathrm{m}$ ) as compared to ultrasonic scaler $(1.727 \mu \mathrm{m})$ and curette group $(1.22 \mu \mathrm{m})$. However, surface with smear layer were found to be maximum $(50 \%)$ in curette treated samples and minimum (20\%) in laser treated ones. Maximum cracks $(83.34 \%)$ were produced by ultrasonic scaler, and minimum $(43.33 \%)$ by curettes. Crater formation was maximum $(50 \%)$ in laser treated samples and minimum $(3.33 \%)$ in curette treated ones. $63.33 \%$ samples treated by laser demonstrated melting of root surface, followed by ultrasonic scaler and curettes.

Conclusion: $\mathrm{Er}, \mathrm{Cr}$ :YSGG laser produced maximum microstructural changes on root surface that can influence the attachment of soft periodontal tissues as well as plaque and calculus deposition. In vivo studies are needed to validate these results and to evaluate their clinical effects.
\end{abstract}

Keywords: Periodontal therapy; Er,Cr:YSGG; Laser; Smear layer; Scaling; Root planing.

planing which constitutes one of the most important stages in surgical and non-surgical treatment of periodontal diseases. Several instruments including curettes, ultrasonic scalers and various types of lasers have been used for this purpose.

Although hand scalers are frequently used, they are time consuming and considerable skill is required to be able to operate them. ${ }^{1}$ Some clinicians find ultrasonics to be 
superior to hand instruments both in smoothness and ability to remove subgingival calculus and plaque. However, thoroughness of debridement is often compromised in deep periodontal pockets. They also have a significant disadvantage of contaminated aerosol formation.

Mechanical root debridement results in formation of smear layer which serves as a barrier between periodontal tissues and root surface, inhibiting the formation of new connective tissue attachment and thus affects the periodontal healing process. To overcome these limitations of curettes and ultrasonic units, many researchers have examined the effects of lasers as an adjunct or alternative to conventional mechanical periodontal therapy. Lasers are one of the most promising modalities for nonsurgical periodontal treatment as they can achieve excellent tissue ablation with strong antimicrobial and detoxification effects. ${ }^{2}$ The most commonly used lasers in periodontics are diode lasers, Neodymium-Doped Yttrium Aluminium Garnet (Nd:YAG), Erbium-Doped Yttrium Aluminum Garnet (Er:YAG), Erbium, Chromium doped Yttrium Scandium Gallium Garnet (Er,Cr:YSGG) and the carbon dioxide $\left(\mathrm{CO}_{2}\right)$ laser.

Erbium lasers can be used for both soft and hard tissue treatment. ${ }^{3}$ This laser works on hydrokinetic theory and has the highest absorption coefficient for water amongst the entire range of lasers presently used in dentistry. The mechanism by which the laser ablates the tissue readily is known as photochemical modulation. ${ }^{4}$ When irradiated with this laser, water in the tissue absorbs the light readily, resulting in massive volume expansion of water molecules. This expansion causes the surrounding matter to literally explode away. Laser-induced changes during tissue ablation include melting and recrystallization resulting in microscopic and macroscopic irregularities. ${ }^{4}$

Results from studies that evaluated the effect of instrumentation on the root surface have shown the difference in terms of the surface roughness they produce. This roughness could influence the bacterial colonization and the adherence of fibroblasts. Several in vivo studies have revealed the evidence of a positive co-relation between the surface roughness and the rate of supragingival plaque accumulation. ${ }^{5,6} \mathrm{~A}$ smooth root surface may be important in the coronal area of the root, in order to avoid subgingival microbial colonization, while a rough root surface may be more desirable in the medium and apical areas to permit regenerative cell attachment. ${ }^{7}$

There are very few studies comparing the effects of Er,Cr:YSGG laser and conventional instruments on the root surface. The aim of the present study was to evaluate and compare the surface characteristics of roots treated with conventional instrumentation and those irradiated with Er,Cr:YSGG laser using scanning electron microscope (SEM) and profilometer.

\section{Methods}

Infection Control Protocol

Immediately after extraction the soft tissue attached to the tooth surface was carefully removed with wet cotton without damaging the root surface. Tooth samples were handled while wearing latex gloves, face mask and protective eyewear. OSHA (Occupational Safety and Health Administration) and CDC (Centre for Disease Control and Prevention) recommendations and guidelines were followed. After collection the samples were transferred to $0.5 \%$ sodium hypochlorite solution in wide mouthed plastic jars for disinfection. The solution was discarded after 30 minutes and the teeth were transferred into separate jars containing the deionized water with thymol.

- The collection jars, lids and gloves were discarded using the biohazard waste management protocol.

- The samples were removed with cotton pliers and rinsed in tap water.

- The samples were dried by placing them over paper towels and blotted for a few minutes before using them for study.

- The paper towels and container jars were discarded into biohazard receptacles.

\section{Specimen Preparation}

Thirty human premolars freshly extracted for orthodontic purpose and with intact root surface were used in the study. After disinfection, teeth were decoronated using carbide bur at high speed under water spray and high volume suction. The mesial surface of each root was divided into 4 parts by making vertical lines in apico-coronal direction of $0.5 \mathrm{~mm}$ depth by tapered fissured diamond bur (Figure 1A). Each part was randomly marked as A, B, C $\& D$ and treated as separate sample. The following groups were made depending on the treatment rendered: Group A: Part A of each tooth which received no treatment. Group B: Part B of each tooth was irradiated by Er,Cr:YSGG laser. Group C: Part C of each tooth was treated by piezoelectric ultrasonic unit. Group D: Part D of each tooth was treated by Gracey curettes.

\section{Er,Cr:YSGG Laser Settings and Treatment}

The Er,Cr:YSGG laser (Waterlase MD, Biolase Technology Inc., CA, USA) with a wavelength of $2780 \mathrm{~nm}$ was operated at $1 \mathrm{~W}$ power, $10 \%$ air and $15 \%$ water settings with $20 \mathrm{~Hz}$ frequency in non-contact mode. The Z6 laser tip with diameter of $600 \mu \mathrm{m}$ and length $6 \mathrm{~mm}$, (Waterlase MD, Biolase Technology Inc., CA, USA) was used for 20 consecutive strokes in 20 seconds (Figure 1B). The strokes were directed apico-coronally starting from the root apex to cemento-enamel junction of the experimental surface.

\section{Ultrasonic Unit Settings and Treatment}

Piezoelectric ultrasonic unit (BonART-P6, BonART Co. Ltd, Taiwan) was used at medium power settings of air at $65 \%$ and water at 55\%. BS-1 tip (Universal Pointed tip) was tangentially applied to the sample for $20 \mathrm{sec}$ onds without any pressure in an apico-coronal direction (Figure 1C). The tip was evaluated after every use. It was considered as dull and consequently replaced when it wore out by $3 \mathrm{~mm}$. 

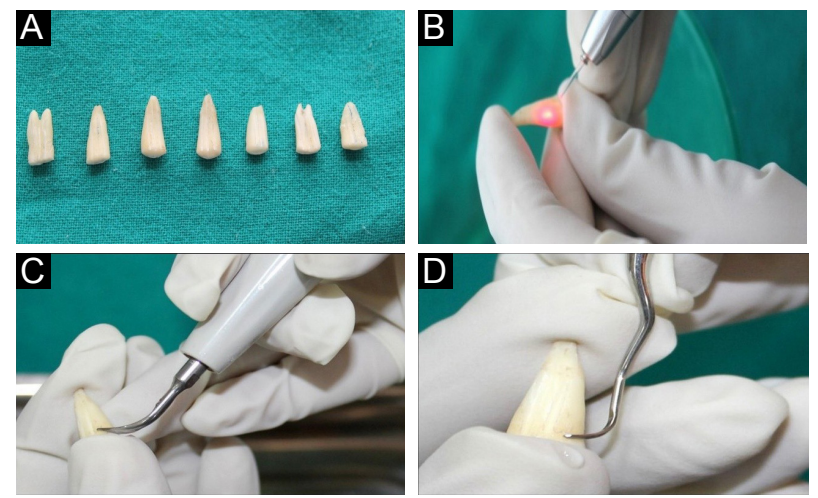

Figure 1. (A) Prepared Samples. (B) Irradiation by Er,Cr:YSGG Laser. (C) Treatment by Ultrasonic Scaler. (D) Treatment by Curette.

\section{Gracey Curette Treatment}

Gracey curette (\#11-12, Hu-Friedy, Chicago, IL, USA) was applied with a moderate to light pull stroke in apicocoronal direction for 20 seconds (Figure 1D). After each use, the sharpness of the curette was evaluated using a sharpness stick test. Dull instruments were sharpened using the instrument sharpener (Sidekick ${ }^{\circledR}$, Hu-Friedy, Chicago, IL, USA).
Analysis of Surface Roughness

Prepared samples were fixed onto wax to avoid accidental movement and the root surface roughness was determined using a surface profilometer (Talysurf CLI, Taylor Hobson, Leicester, UK). Sharp stylus with spherical tip was drawn across each part of tooth at a constant speed for a distance of $2 \mathrm{~mm}$, starting $2 \mathrm{~mm}$ apical to CEJ. A 2CR filter was used to separate the components of a surface profile, high frequency corresponded with roughness and low frequency corresponded with radicular waviness. The roughness average ( $\mathrm{Ra}$ ), defined as the mean between peaks and valleys of the surface profile ${ }^{8}$ was determined for each part. After obtaining the Ra value of each part of every specimen, the mean roughness value $(\mathrm{Ra})$ was calculated.

Scanning Electron Microscope Evaluation

Since the samples were non-conductive, a sputtering ion device was used to make them conductive followed by examination under SEM (LEO 435 VP, LEO Electron Microscopy Ltd, Cambridge, UK). The surface was scanned and observed on the fluorescent screen at 10X, 40X and 100X magnifications (Figure 2). Samples were analyzed for the following objective parameters: (a) Presence of smear layer on the root surface, $(b)$ Crater formation, $(c)$
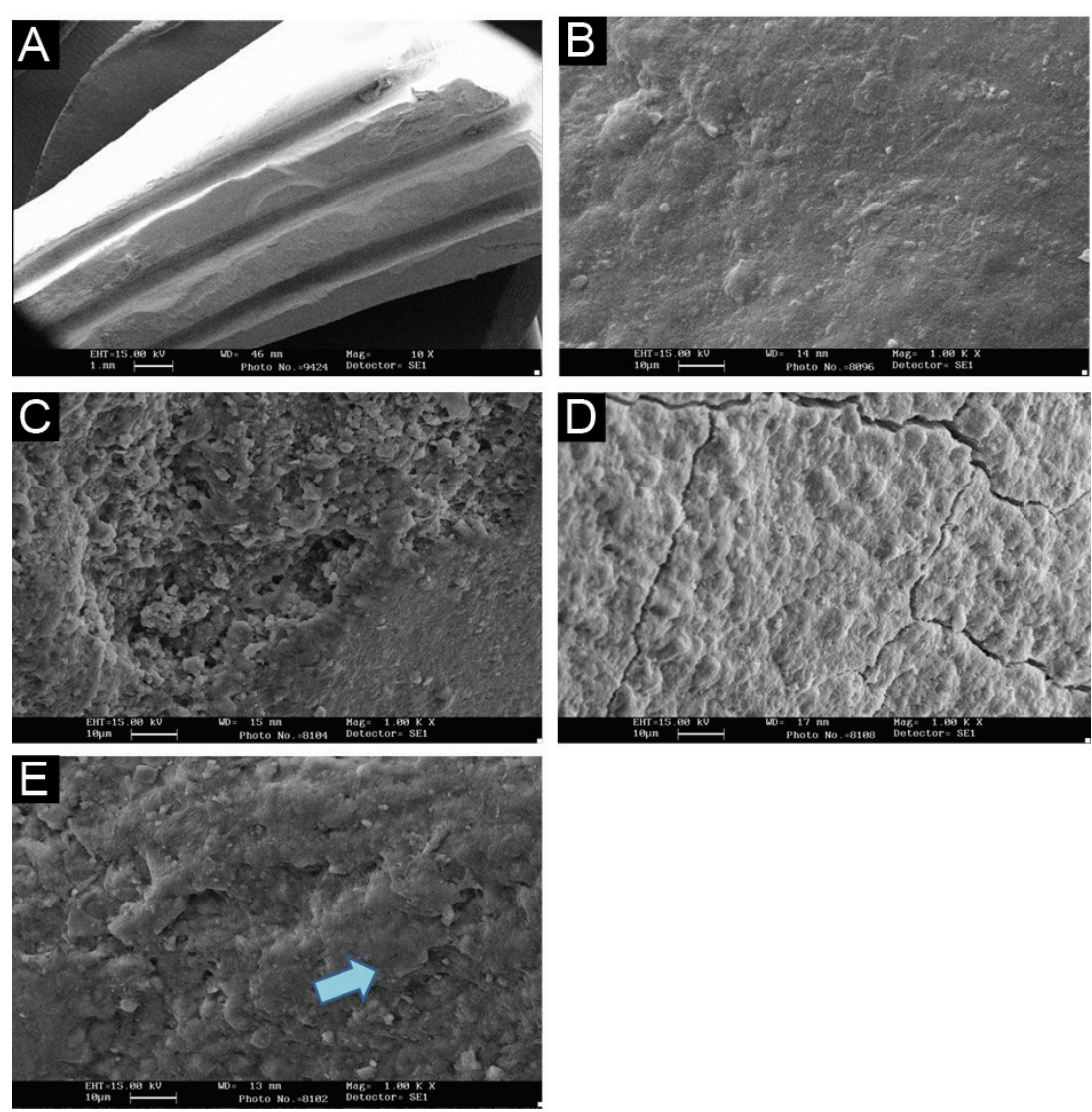

Figure 2. (A) SEM Photomicrograph Showing Division of Surface (Magnification: 10X). (B) SEM Photomicrograph of Control Group Showing Absence of Smear Layer (Magnification: 1000X). (C) SEM Photomicrograph of Ultrasonic Scaler Treated Sample Showing Presence of Cracks (Magnification: 1000X). (D) SEM Photomicrograph of Ultrasonic Scaler Treated Sample Showing Presence of Craters (Magnification: 1000X). (E) SEM Photomicrograph of Laser Irradiated Sample Showing Presence of Cracks (Magnification: 1000X) 


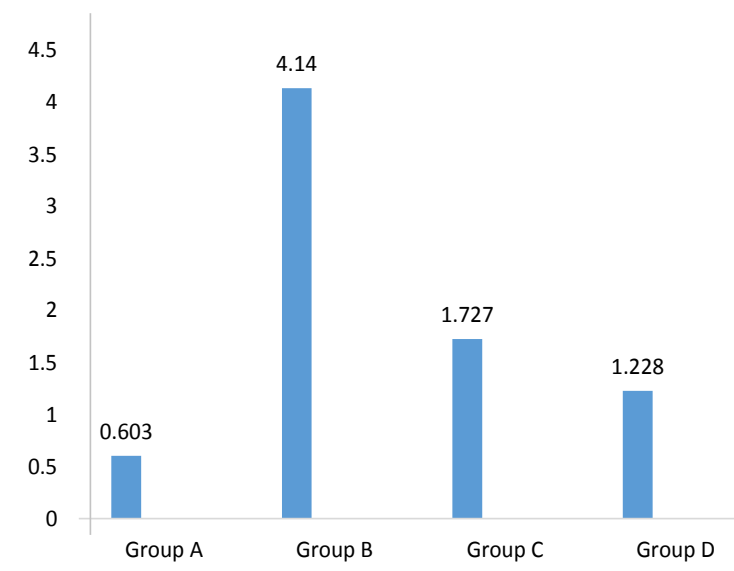

Figure 3. Mean Value of Surface Roughness (Ra) in 4 Groups.

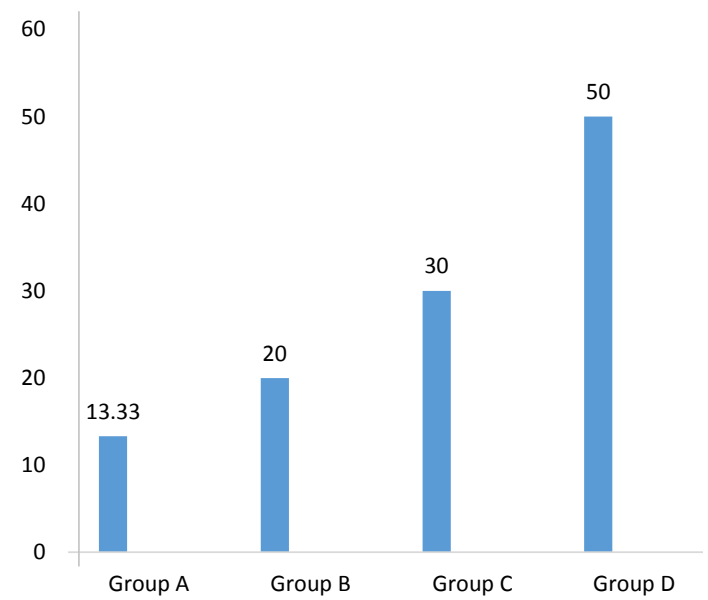

Figure 4. Percentage Distribution of Smear Layer in 4 Groups.

Table 1. Intergroup Comparison for Presence of Smear Layer

\begin{tabular}{lcc}
\hline $\begin{array}{l}\text { Intergroup } \\
\text { Comparison }\end{array}$ & $\boldsymbol{P}$ Value & $\begin{array}{c}\text { Significant (S) or Non- } \\
\text { significant (N) }\end{array}$ \\
\hline Group A/B & 0.15 & $\mathrm{~N}$ \\
Group A/C & 0.19 & $\mathrm{~N}$ \\
Group A/D & 1.00 & $\mathrm{~N}$ \\
Group B/C & 0.43 & $\mathrm{~N}$ \\
Group B/D & 0.015 & $\mathrm{~S}$ \\
Group C/D & 0.19 & $\mathrm{~N}$ \\
\hline
\end{tabular}

Crack formation, $(d)$ Melting of dentin (Figures 2A-E). Results of profilometer and SEM analysis were analyzed statistically to compare the effects of different modalities.

\section{Results}

Chi-square test was used for comparison between the groups. The chi-square test was applied to compare the proportion of positivity across the groups and also for the pair wise comparison. Pair-wise comparison across the groups was considered significant when $P$ value was $<0.02$ instead of 0.05 because multiple comparisons were made.

Surface Roughness

Profilometer analysis showed that minimum surface

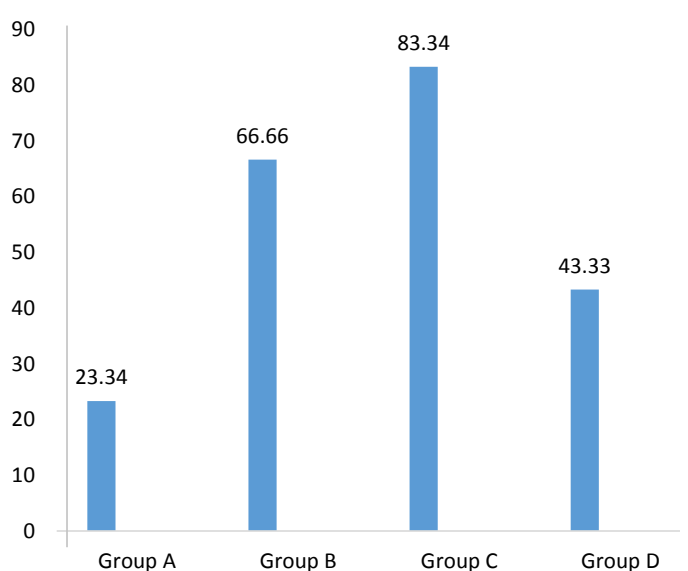

Figure 5. Percentage Distribution of Cracks in 4 Groups.

Table 2. Intergroup Comparison for Presence of Cracks

\begin{tabular}{lcc}
\hline $\begin{array}{l}\text { Intergroup } \\
\text { Comparison }\end{array}$ & $\boldsymbol{P}$ Value & $\begin{array}{c}\text { Significant (S) or Non- } \\
\text { significant (N) }\end{array}$ \\
\hline Group A/B & 0.002 & $\mathrm{~S}$ \\
Group A/C & 0.000 & $\mathrm{~S}$ \\
Group A/D & 0.236 & $\mathrm{~N}$ \\
Group B/C & 0.136 & $\mathrm{~N}$ \\
Group B/D & 0.426 & $\mathrm{~S}$ \\
Group C/D & 0.024 & $\mathrm{~N}$ \\
\hline
\end{tabular}

roughness (mean $\mathrm{Ra}=0.603$ ) was present in uninstrumented samples i.e., group A (control group). Among all the instrumented surfaces, group B (Er,Cr:YSGG laser) showed greatest roughness (mean $\mathrm{Ra}=4.14 \mu \mathrm{m}$ ) when compared to group $\mathrm{C}$ (ultrasonic unit, mean $\mathrm{Ra}=1.727$ $\mu \mathrm{m}$ ) and group $\mathrm{D}$ (curette, mean $\mathrm{Ra}=1.228 \mu \mathrm{m}$ ) (Figure 3 ). Dunnett test was applied for multiple group comparisons. All the inter-group differences were statistically significant.

\section{Presence of Smear Layer}

The presence of smear layer was evaluated by SEM and found to be present in $13.33 \%$ samples of group A, $20 \%$ samples of group B, 30\% samples of group C and $50 \%$ samples of group D (Figure 4). The intergroup comparison showed no significant difference except for groups $\mathrm{B}$ and $\mathrm{D}$ where the difference was significant $(P=0.015)$ (Table 1). Hence among the instrumentation groups laser showed minimum presence of smear layer while curette showed maximum presence of smear layer.

Presence of Cracks

$23.34 \%$ of the untreated samples i.e., group A showed the presence of cracks. Among the test groups, group B showed crack formation in $66.66 \%$ samples, group C in $83.34 \%$ samples and group D in $43.33 \%$ samples (Figure $5)$. It was observed that the ultrasonic scaler produced maximum cracks whereas curette produced minimum (Table 2).

Presence of Crater Formation

Craters were totally absent in control group i.e., in group 


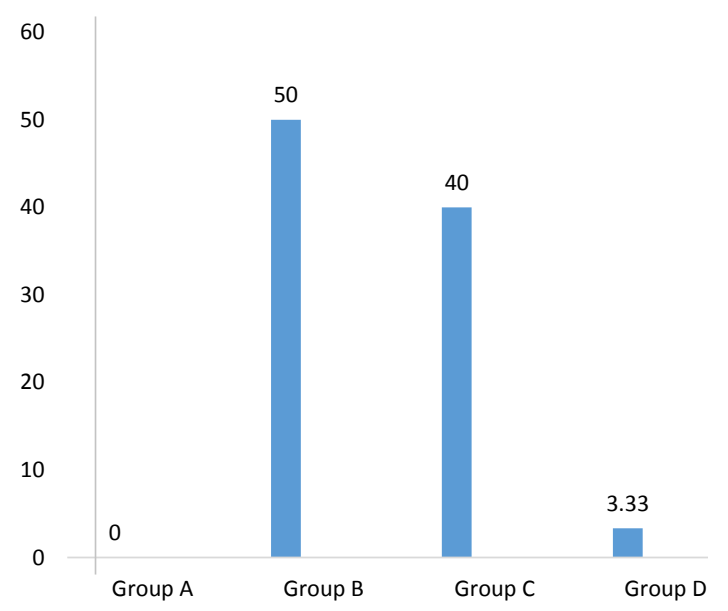

Figure 6. Percentage Distribution of Craters in 4 Groups.

Table 3. Intergroup Comparison for Presence of Craters

\begin{tabular}{lcc}
\hline $\begin{array}{l}\text { Intergroup } \\
\text { Comparison }\end{array}$ & $\boldsymbol{P}$ Value & $\begin{array}{c}\text { Significant (S) or Non- } \\
\text { significant (N) }\end{array}$ \\
\hline Group A/B & 0.000 & $\mathrm{~S}$ \\
Group A/C & 0.000 & $\mathrm{~S}$ \\
Group A/D & 1.000 & $\mathrm{~N}$ \\
Group B/C & 0.436 & $\mathrm{~N}$ \\
Group B/D & 0.000 & $\mathrm{~S}$ \\
Group C/D & 0.000 & $\mathrm{~S}$ \\
\hline
\end{tabular}

A. Increase in presence of craters was seen after instrumentation in all the treated groups. Group B showed crater formation in $50 \%$ samples, group $\mathrm{C}$ in $40 \%$ and group $\mathrm{D}$ in $3.33 \%$ of samples (Figure 6). It was observed that laser produced maximum number of craters and curette produced the least (Table 3 ).

\section{Melting of Surface}

On SEM evaluation, no melting was observed in group A and group D. Group B demonstrated highest melting (63.66\%). Group C was intermediate (13.33\%) among the treated surfaces (Figure 7). It was observed that laser irradiation produced more melting of surface as compared to other modalities (Table 4).

\section{Discussion}

Biologically acceptable smooth and hard root surface is considered to be the desired end point of scaling and root planing. It facilitates a surface free of plaque and calculus, which is a pre-requisite in long term maintenance of periodontal health. There has been a wide range of instruments used for this purpose. However, there are important considerations in their use including the amount of root surface removed and the resultant surface roughness. The present work evaluated the effect of Er,Cr:YSGG laser, ultrasonic scaler and curette on root surface morphology using profilometer and SEM. The test and control sites were taken on the same surface of a tooth to eliminate the confounding bias expected due to varying morphology of cementum on different surfaces and on different teeth. The method and time of instrumentation were standard-

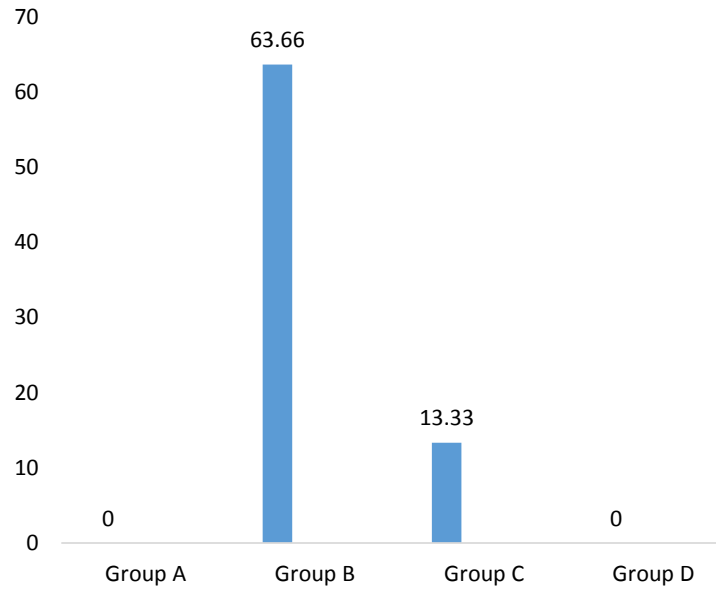

Figure 6. Percentage Distribution of Surface Melting in 4 Groups.

Table 4. Intergroup Comparison for Presence of Surface Melting

\begin{tabular}{lcc}
\hline $\begin{array}{l}\text { Intergroup } \\
\text { Comparison }\end{array}$ & $\boldsymbol{P}$ Value & $\begin{array}{c}\text { Significant (S) or Non- } \\
\text { significant (N) }\end{array}$ \\
\hline Group A/B & 0.000 & $\mathrm{~S}$ \\
Group A/C & 0.110 & $\mathrm{~S}$ \\
Group A/D & 1.000 & $\mathrm{~N}$ \\
Group B/C & 0.000 & $\mathrm{~N}$ \\
Group B/D & 0.000 & $\mathrm{~S}$ \\
Group C/D & 0.110 & $\mathrm{~S}$ \\
\hline
\end{tabular}

ized to simulate clinical scenario of application of instruments on root surface for identical period of time.

The Ra values showed the mean surface roughness of 0.63 $\mu \mathrm{m}$ in control group. This finding was similar to that reported by Folwaczny et al, who found the mean Ra value of $0.53 \mu \mathrm{m}$ on healthy, untreated root surface. ${ }^{9}$

Mean $\mathrm{Ra}$ values were maximum $(4.14 \mu \mathrm{m})$ in group $\mathrm{B}$ i.e., Er,Cr:YSGG laser treated surface. Photochemical modulation $^{4}$ along with exposed dentinal tubules due to removal of smear layer, and development of fissures and cracks could be a possible explanation for the increase in Ra value for this group. ${ }^{10}$ External irrigation was also used while irradiating the root surface with laser, as it produces a cleaner and comparatively smoother surface. ${ }^{11}$ Laser was used in defocused, non-contact mode as it effectively removes calculus with only minimal removal of cementum and less production of heat. ${ }^{12}$

The results (mean $\mathrm{Ra}=1.72$ ) for group $\mathrm{C}$ (ultrasonic scaler) were in agreement with previous studies which showed higher mean Ra values for ultrasonic group compared to the hand instrumented group. These profilometer findings were supported by the SEM studies which showed a stippled roughened appearance of surface similar to etching. ${ }^{13}$ It has been suggested that the erosive nature of the cavitational activity together with acoustic microstreaming preferentially removed the harder brittle inorganic constituents of dentin and cementum leaving behind the softer organic structure. ${ }^{13,14}$ Flemmig et $\mathrm{al}^{15}$ found that ultrasonic units' increased lateral force and angulation resulted in greater substance removal, while increasing instruments' power settings did not. 
The smoothest surface was seen in group D (hand instrumentation) with average surface roughness value $(\mathrm{Ra})$ of $1.2 \mu \mathrm{m}$. Thus different Ra values produced by different modalities can be attributed to their different mechanism of actions. Schlageter et $\mathrm{al}^{16}$ reported that instruments whose working stroke is of scraping nature creates and leaves behind the smoother root surface compared to instruments with oscillating movement.

In the present study, the mean surface roughness for root surfaces treated with any of the 3 modalities was found to be above the critical threshold Ra value. According to several previous investigations, the surface roughness appears to cause significant effects in vivo when the mean surface roughness exceeds a certain value $(0.2 \mu \mathrm{m}) .{ }^{6}$ Bollen et al evaluated the additional effect of a further smoothening of intra-oral hard surfaces on clinical and microbiological parameters in a short-term experiment. The results indicated that a reduction in surface roughness below $\mathrm{Ra}=0.2$ $\mu \mathrm{m}$, the so-called threshold Ra, had no further effect on the quantitative/qualitative microbiological adhesion or colonisation, neither supra- nor subgingivally. ${ }^{17}$

Thus, it can be assumed that the root surfaces treated with any modality may lead to a significant risk for plaque deposition and, subsequently, to the occurrence of clinical inflammation at the marginal periodontium. Therefore, to achieve the ideal surface roughness of root surfaces that have been treated, several authors have recommended the polishing of root surfaces using rubber cups and polishing pastes following scaling and root planing. ${ }^{18}$

Smear layer was absent in $80 \%$ of specimens treated with laser which is comparable to the control group. Similar findings were observed by Aoki et $\mathrm{al}^{19}$ and Ting et al. ${ }^{20}$ Hence, laser appears to provide excellent tissue ablation with strong bactericidal and detoxification effects without producing the smear layer and presented favorable conditions for attachment of periodontal tissue. ${ }^{21}$

Almost one-third of the surfaces treated with ultrasonic scalers showed presence of smear layer, similar to the findings reported by Gómez et al. ${ }^{22}$ Presence of smear layer was even higher (50\%) among the surfaces treated with curettes. Theodoro et $\mathrm{l}^{23}$ have reported similar pattern. This finding could be explained by the fact that curettes remove several layers of root substance with greater contact area.

The cracks developed by laser irradiation produce an etched root surface, which may lead to faster adhesion and growth of periodontal tissues. ${ }^{24}$ However, in the present study, laser produced minimum crack formation among all treated surfaces. Guilherme et $\mathrm{al}^{25}$ have shown an $\mathrm{ab}$ sence of cracks on root surfaces treated with Er,Cr:YSGG laser.

Crater formation, as a result of the opening of dentinal tubules may present favourable conditions for recolonization of pathogenic bacteria. ${ }^{26}$ Laser treated surfaces presented with maximum craters (50\%), while curettes produced the smoothest surfaces. Renato et $\mathrm{al}^{27}$ suggested that greater contact area during instrumentation by $\mathrm{cu}-$ rette produces a smoother surface.
Around two-thirds of laser treated samples presented surface melting. Similar findings were reported by Fujii et $\mathrm{al}^{28}$ who observed that even at minimal energy levels, lasers caused melting of the hydroxyapatite crystals which reached steaming temperature and causes micro explosion by ejecting the molten mineral phase. The lased cementum surface displays a characteristic microstructure with denaturation of collagen fibres and reduction of organic components. Melting of peritubular dentin may cause closure of dentinal tubules and reduce dentinal hypersensitivity. ${ }^{29}$ Frentzen et $\mathrm{al}^{30}$ also reported the melting of superficial layers of tooth after irradiation with Er:YAG laser at $14.2 \mathrm{~J} / \mathrm{cm}^{2}$ per pulse and frequency of $10 \mathrm{~Hz}$ under water irrigation. In contrast, Aoki et $\mathrm{al}^{31}$ reported that Er;YAG laser treated surface exhibits a micro-irregular appearance without melting.

In the surfaces treated with ultrasonic scalers, melting was seen in $13.33 \%$ of samples. This finding has not been reported previously and may be attributed to the inadvertent thermal effect of the laser beam which was used on the adjacent part $\mathrm{B}$.

In the present study, the surface roughness data obtained from SEM images confirmed the results obtained from profilometry as whenever there were craters, cracks, and melting present, Ra value was also found to be increased. Lasers have been shown to efficiently remove the calculus and diseased cementum from the root surface. Detoxification and antimicrobial properties of laser have an added advantage over other modalities. Roughness of root surface can be beneficial or harmful for the periodontal health, depending on the part of root surface instrumented. High Ra value obtained by laser treatment may lead to the biofilm formation in coronal part of root surface but at the same time it may be beneficial in regenerative cell attachment in the middle and apical third by facilitating cell adhesion and proliferation thereby accelerating new attachment formation. ${ }^{31}$

Thus, within limits of the present study, it was found that all modalities i.e., curettes, ultrasonic scalers and the Er,Cr:YSGG laser increase the surface roughness of the root surface. In addition, the laser has produced rougher surfaces and maximum change in the root surface profile. Melting of the surface is a more noteworthy finding and will require further evaluation.

\section{Conclusion}

Despite the successful experimental results, there is still insufficient scientific evidence of a superior clinical efficacy of Er,Cr:YSGG laser on dental root surface, compared to other conventional modalities and to what extent these findings influence the bacterial and cellular adhesion, or how they affect the clinical outcomes. Further in vitro and in vivo investigations need to be carried out to evaluate this aspect of our results.

\section{Ethical Consideration}

Present study was approved by the ethical committee of Maulana Azad Institute of Dental Sciences, New Delhi. 


\section{Conflict of Interests}

Authors declare that they have no competing interests.

\section{References}

1. Yukna RA, Scott JB, Aichelman ME. Clinical evaluation of the speed and effectiveness of subgingival calculus removal on single rooted teeth with diamond-coated ultrasonic tips. $J$ Periodontol. 1997;68:436-442. doi:10.1902/jop.1997.68.5.436.

2. Oda S, Nitta H, Setoguchi T, Izumi Y, Ishikawa I. Current concepts and advances in manual and power-driven instrumentation. Periodontology 2000. 2004;36:45-58. doi:10.1111/j.1600-0757.2004.03674.x.

3. Cobb CM. Lasers in periodontics:a review of the literature. $J$ Periodontol. 2006;77:545-564. doi:10.1902/jop.2006.050417.

4. Koort HJ, Frentzen M. Laser Effects on Dental hard tissue. In: Miserendio LJ, Pick RM, eds. Lasers in Dentistry. Chicago: Quintessence; 1995:57-70.

5. Shafagh, I. Plaque accumulation on cast gold complete crowns polished by a conventional and an experimental method. J Prosth Dent. 1986;55:339-342. doi:10.1016/00223913(86)90116-2.

6. Quirynen M, Bollen CML, Papaioannou W, Van Eldere J, Van Steenberghe D. The influence of titanium abutment surface roughness on plaque accumulation and gingivitis:short-term observations. Int J Oral Maxillofac Implants. 1996;11:169178. doi:10.1034/j.1600-0501.1996.070302.x.

7. de Mendonça AC, Máximo MB, Rodrigues JA, Arrais CA, de Freitas PM, Duarte PM. Er:YAG Laser, ultrasonic system, and curette produce different profiles on dentine root surfaces: an in vitro study. Photomed Laser Surg. 2008;26(2):91-97. doi:10.1089/pho.2007.2129.

8. Leitao J, Hegdahl T. On the measuring of roughness. Acta Odontol Scand. 1981;48:409-413.

9. Folwaczny M, George G, Thiele L, Mehl A, Hicke R. Root surface roughness following Er:YAG laser irradiation at different radiation energies and working tip angulations. J Clin Periodontol. 2002;29:598-603. doi:10.1034/j.1600051x.2002.290703.x.

10. Roulet JF, Mehrens TK. The surface roughness of restorative materials and dental tissues after polishing with prophylaxis and polishing pastes. J Periodontol. 1982;53:157-266.

11. Katia MS, Akira A, Shizuko I, Isao I. Morphological analysis of cementum and root dentin after Er:YAG laser irradiation. Lasers Surg Med. 2002;31:79-85. doi:10.1002/1sm.10074.

12. Crespi R, Romanos GE, Barone A, Sculean A, Covani U. Er:YAG laser In defocused mode for scaling of periodontally involved root surfaces:an in vitro pilot study. J Periodontol. 2005;76(5):686-90. doi:10.1902/jop.2005.76.5.686

13. Walmsley AD, Walsh TF, Laird WR, Williams AR. Effects of cavitational activity on the root surface of teeth during ultrasonic scaling. J Clin Periodontol. 1990;17(5):306-312. doi:10.1111/j.1600-051x.1990.tb01094.x.

14. Khambay BS, Walmsley AD. Acoustic microstreaming:detection and measurement around ultrasonic scalers. J Periodontol. 1999;70(6):626-631. doi:10.1902/jop.1999.70.6.626.

15. Flemmig TF, Petersilka GJ, Mehl A, Hickel R, Klaiber B. Working parameters of a magnetostrictive ultrasonic scaler influencing root substance removal in vitro. J Periodontol. 1998;69:547-553.

16. Schlageter T, Rateitschak-Plüss EM, Schwarz JP. Root surface smoothness or roughness following open debridement. An in vivo study. J Clin Periodontol. 1996;23(5):460-464. doi:10.1902/jop.1998.69.5.547.
17. Bollen CM, Papaioanno W, Van Eldere J, Schepers E, Quirynen M, van Steenberghe D. The influence of abutment surf ace roughness on plaque accumulation and per implant mucositis. Clin Oral Implants Res. 1996;7:201-211.

18. Pattison AM, Pattison GL. Scaling and Root planing. In: Newman MG, Takei HH, Klokkevold PR, Carranza FA, eds. 11th ed. Carranza's Clinical Periodontology. Philadelphia: WB Saunders; 2012:461-473.

19. Aoki A, Ando Y, Watanabe H, Ishikawa I. In vitro studies on laser scaling of subgingival calculus with an erbium:YAG laser. J Periodontol. 1994;65(2):1097-1106. doi:10.1902/ jop.1994.65.12.1097.

20. Ting CC, Fukuda M, Watanabe T, Aoki T, Sanaoka A, Noguchi T. Effects of Er,Cr:YSGG laser irradiation on the root surface:morphologic analysis and efficiency of calculus removal. J Periodontol. 2007;78(11):2156-2164. doi:10.1902/ jop.2007.070160.

21. Polson AM, Caton J. Factors influencing periodontal repair and regeneration. J Periodontol. 1982;53(10):617-625. doi:10.1902/jop.1982.53.10.617.

22. Gómez C, Bisheimer M, Costela A, García-Moreno I, García A, García JA. Evaluation of the effects of Er:YAG and Nd:YAG lasers and ultrasonic instrumentation on root surfaces. Photomed Laser Surg. 2009;27:43-8.

23. Theodoro LH, Sampaio JE, Haypek P, Bachmann L, Zezell DM, Garcia VG. Effect of Er:YAG and Diode lasers on the adhesion of blood components and on the morphology of irradiated root surfaces. J Periodontal Res. 2006 ;41(5):38190. doi:10.1111/j.1600-0765.2005.00846.x.

24. Feist I, Micheli G, Carneiro S, Eduardo C, Miyagi S, Marques M. Adhesion and growth of cultured human gingival fibroblasts on periodontally involved root surfaces treated by Er:YAG laser. J Periodontol. 2003;73(9):1368-1375. doi:10.1902/jop.2003.74.9.1368.

25. Guilherme J, José E, Rosemary A. Effects of Er,Cr:YSGG laser irradiation on root surfaces for adhesion of blood components and morphology. Photomed Laser Surg. 2010;28(6):751-756. doi:10.1089/pho.2009.2681.

26. Adriaens PA, Edwards CA, De Boever JA, Loesche WJ. Ultrastructural observations on bacterial invasion in cementum and radicular dentin of periodontally diseased human teeth. J Periodontol. 1988;59(8):493-503. doi:10.1902/ jop.1988.59.8.493.

27. Renato CV, Ribeiro FR, Sallum AW, Sallum EA, NocitiJr FH, Casati MZ. Root surface defect produced by hand instruments and ultrasonic scaler with different power settings: an in vitro study. Braz Dent J. 2009;20(1):58-63. doi:10.1590/s0103-64402009000100010.

28. Fujii T, Baehni PC, Kawai O, Kawakami T, Matsuda K, Kowashi Y. Scanning electron microscopic study of the effects of Er:YAG laser on root cementum. $J$ Periodontol. 1998;69(11):1283-1290. doi:10.1590/s010364402009000100010 .

29. Gholami GA, Fekrazad R, Esmaiel-Nejad A, Kalhori AM. An evaluation of the occluding effects of Er;Cr:YSGG, Nd:YAG, $\mathrm{CO}_{2}$ and diode lasers on dentinal tubules:a scanning electron microscope in vitro study. Photomed Laser Surg. 2011;29(2):115-121. doi:10.1089/pho.2009.2628.

30. Frentzen M, Braun A, Aniol D. Er:YAG laser scaling of diseased root surfaces. J Periodontol. 2002;73(5):524-530. doi:10.1902/jop.2002.73.5.524.

31. Aoki A, Sasaki KM, Watanabe H, Ishikawa I. Lasers in non-surgical periodontal therapy. Periodontology 2000. 2004;36:59-97. doi:10.1111/j.1600-0757.2004.03679.x. 